\title{
Salivary Steroid Changes and Physical Performance in Highly Trained Cyclists
}

\author{
J. A. López Calbet I, M. A. Navarro ${ }^{2}, J . R$. Barbany ${ }^{3}, J$. Garcia Manso $^{\prime}, M . R$. Bonnin ${ }^{2}$, J. Valero $^{2}$ \\ ${ }^{1}$ Human Performance Laboratory, Physical Education Department, Universidad de Las Palmas de Gran Canaria \\ ${ }^{2}$ Hormone Unit (Biochemistry Service), Ciudad Sanitaria de Bellvitge, Barcelona \\ ${ }^{3}$ Medical Sciences Department, INEFC, Barcelona, Spain
}

\begin{abstract}
J. A. López Calbet, M. A. Navarro, J. R. Barbany, J. Garcia Manso, M. R. Bonnin and J. Valero, Salivary Steroid Changes and Physical Performance in Highly Trained Cyclists. Int J Sports Med, Vol 14, No 3, pp 111-117, 1993.

Accepted after revision: January 7, 1983

The purpose of this work was to study the seasonal salivary cortisol and testosterone changes, and their relationships with lean body mass variations, in highly trained cyclists. Physical fitness, body composition (6 skinfolds) and basal salivary testosterone were evaluated in 7 male cyclists, on two separate occasions. The first assessment was made at the onset of the competitive season and the second 6 months later. Two kinds of exercise tests were carried out. The first test was an incremental exercise test to determine the maximum $\mathrm{O}_{2}$ consumption $\left(\mathrm{VO}_{2} \max \right)$ and the maximum workload (Wmax). We also measured the $\mathrm{VO}_{2}$ and workload (W) attained at the first and second ventilatory thresholds $\left(\mathrm{VO}_{2} \mathrm{VT}_{1}\right.$, $\mathrm{WVT}_{1}, \mathrm{VO}_{2} \mathrm{VT}_{2}, \mathrm{WVT}_{2}$ ). During the tests the $\mathrm{VO}_{2}$ was recorded every 30 seconds (Oxycon-5, Mijhardt BV, Odijk). As a second test two days later, we assessed the anaerobic capacity expressed as the maximal accumulated $\mathrm{O}_{2}$ deficit (MAOD). Briefly, each subject underwent five submaximal exercises each lasting $6 \mathrm{~min}$ at an intensity of 200, 220, 240, 260 and $280 \mathrm{~W}$. We estimated individually the $\mathrm{O}_{2}$ demand by extrapolating the linear relationship between the power and the $\mathrm{O}_{2}$ demand previously established. Afterwards the subjects

consumed during the supramaximal rides. We found a significant increase in some physical fitness parameters related to aerobic capacity. The Wmax increased from $5.7 \pm 0.5$ to $6.1 \pm$ $0.3 \mathrm{~W} \cdot \mathrm{kg}^{-1}(\mathrm{p}<0.05)$; the $\mathrm{WVT}_{2}$ increased from $3.6 \pm 0.5$ to $4.0 \pm 0.5 \mathrm{~W} \cdot \mathrm{kg}^{-1}\left(\mathrm{p}<0.05\right.$; the $\mathrm{WVT}_{2}$ increased from $4.4 \pm 0.6$ to $4.9 \pm 0.4 \mathrm{~W} \cdot \mathrm{kg}^{-1}(\mathrm{p}<0.05)$. The $\mathrm{VO}_{2} \max$ (from $75.7 \pm 4.8$ to $75.3 \pm 3.5 \mathrm{ml} \cdot \mathrm{kg}^{-1} \cdot \mathrm{min}^{-1}, \mathrm{p}=\mathrm{NS}$ ), the $\mathrm{VO}_{2} \mathrm{VT}_{1}$ (from 51.7 \pm 6.2 to $54.1 \pm 5.3 \mathrm{ml} \cdot \mathrm{kg}^{-1} \cdot \mathrm{min}^{-1}, \mathrm{p}=\mathrm{NS}$ ), and the $\mathrm{VO}_{2} \mathrm{VT}_{2}$ (from $62.5 \pm 7.2$ to $65.1 \pm 3.4, p=N S$ ) showed a non-significant increasing pattern. Nevertheless, the anaerobic capacity (expressed as the MAOD) decreased from $75.8 \pm 13.9$ to 53.3 $\pm 16.6 \mathrm{ml} \cdot \mathrm{kg}^{-1}(\mathrm{p}<0.05)$. The cycling economy, as reflected by the steady state $\mathrm{VO}_{2}$ at $240 \mathrm{~W}$, ameliorated slightly (from $55.5 \pm 5.3$ to $53.5 \pm 3.2 \mathrm{ml} \cdot \mathrm{kg}^{-1} \cdot \mathrm{min}^{-1}, \mathrm{p}=\mathrm{NS}$ ), but the changes were non-significant. The subjects showed a significant decrease in weight (from $64.3 \pm 3.6$ to $62.5 \pm 3.6 \mathrm{~kg}, \mathrm{p}<$ 0.05 ) and in lean body mass (from $60.4 \pm 3.5$ to $58.4 \pm 3.0 \mathrm{~kg}$, $\mathrm{p}<0.05$ ). Salivary testosterone showed a non-significant decreasing pattern (from $0.45 \pm 0.17$ to $0.39 \pm 0.18 \mathrm{nmol} / 1, \mathrm{p}=$ 0.15 ). The testosterone/cortisol ratio decreased by $29 \%$ (from $0.022 \pm 0.010$ to $0.016 \pm 0.005, \mathrm{p}<0.10$ ), but this change did not reach statistical significance. A firm correlation was found between increment of testosterone and increment of lean body mass $(r=0.87, p<0.05)$. Our cyclists increased their aerobic capacity, but they showed a deterioration of the anaerobic capacity. In spite of the high volume of exercise accumulated by these cyclists, the diminishing effect of endurance training on testosterone was not significantly evident. Our findings suggest that basal bioavailable testosterone changes are related to lean body mass variations.
\end{abstract} performed a supramaximal bout at an intensity producing exhaustion between 2 and 4 minutes. The accumulated $\mathrm{O}_{2}$ demand was calculated by multiplying the $\mathrm{O}_{2}$ demand by the supramaximal test duration. The MAOD was computed as the difference between the accumulated $\mathrm{O}_{2}$ demand and the $\mathrm{O}_{2}$

\section{Introduction}

In recent years it has been shown that intensive training, specially endurance training, may affect the normal function of the reproductive system. Exercise induced-amenorrhea is conspicuous and easily distinguishable, so women have been studied more often. It seems that chronic exercise may

\section{Key words}

Salivary cortisol, salivary testosterone, anaerobic capacity, cycling economy, endurance training

cause an inhibition of the hypothalamic-pituitary-ovarian axis that has been associated with amernorrhea and other forms of menstrual dysfunction, anovulation, inadequate luteal phase, as well as decreased estradiol levels $(8,16)$.

Recently, endocrinologists have begun to study the effects of physical activity on the male endocrine system. Some authors have reported an association between high volume endurance training and reduced levels of serum testosterone, both free and bioavailable $(11,13,30,33,36)$. 
Beyond the apparent banality of these hormonal changes lies the possibility of developing some pathological conditions, like, for example, osteoporosis in women (9). However, in males few data on the pathophysiological effects of a slight hormonal changes associated with endurance training are available.

The maintenance of muscle mass depends on the balance between the anabolic and the catabolic hormones. It is well known that castration in males produces a dramatic diminution of testosterone and lean body mass, specially the muscle mass. Testosterone administration, particularly in the course of strength training, in contrast, may increase muscle mass (12). Some investigators support the concept that the plasma testosterone/cortisol ratio plays an important role in trainability and the maintenance of performance during prolonged training periods $(1,27,34)$.

Usually, endurance training provokes fat body mass to decrease, in previously sedentary subjects, but the changes of these parameters are less apparent in top athletes Since the evolution of the body mass components is dependent on the influence of the hormonal milieu, it seems appropriate to analyze both aspects simultaneously.

The present work is a prospective study on the effects of endurance training on the levels of cortisol and testosterone in saliva, and the relationships between the hormonal changes and body mass variations in top level cyclists analyzed on two separate occasions during one season.

\section{Material and Methods}

\section{Subjects}

Seven male cyclists aged $21 \pm 3$ years and weighing $64.8 \pm 3.7 \mathrm{~kg}$, served as test subjects. After a full description of the procedures, benefits and risk involved in this investigation, they agreed to participate in the study. None had clinically evident cardiovascular disease, acute illness or active chronic systemic disease.

All of them were active cyclists participating in amateur competitions at national level with the exception of one professional. The overall distance covered (races and trainings considered altogether) during the 6 month period was $12,414 \pm$ $4,204 \mathrm{~km}$, the weekly schedule ranged between 300 and $750 \mathrm{~km}$. They usually took part in two races each weekend, ranging between 100 and $150 \mathrm{~km}$. During the 6 months they accumulated a races volume of $4528 \pm 2803 \mathrm{~km}$. No reliable information was available about the relative intensity of each training season. In addition, they participated in 5 to 8 competitions lasting from 3 to 7 days.

The subjects were instructed to follow similar diets and abstain from sexual activities (i.e. sexual intercourse or masturbation) and lessen physical activities for 48 hours prior to the evaluations.

\section{Procedures}

Body composition, physical fitness, and basal salivary steroids were evaluated on two separate occasions. The first assessment was made at the onset of the competitive season in February, and the second, 6 months later, in August.
Body composition was assessed by anthropometric procedures. Skinfold thickness was measured with the test subjects standing according to Wilmore and Behnke (37). The value used for analysis was the average of three measurements obtained, on the right side of the body, with a Harpenden skinfold caliper at the subscapular, triceps, abdominal, suprailiac, midthigh and calf sites. The Yuhasz equation (4) was used for determining body density. The percentage of body fat was calculated from body density by means of the Siri's equation (28). The lean body weight was obtained by subtracting body fat from body weight.

Physical fitness was analyzed by means of two kinds of test. Firstly, we evaluated the aerobic capacity by using an incremental bicycle ergometer exercise test (Monark 818, Varberg, Sweden). The initial load was set at 100 watts and increased by 20 watts every minute until exhaustion. The subjects were instructed to keep a fixed pedal rate of 90 revolutions per minute (rpm). During the tests, ventilatory and gas exchange parameters were monitored every 30 seconds by an open-circuit sampling system (Oxycon-5, Mijhardt BV, Odijk, The Netherlands). We considered as maximum workload (Wmax) the last load sustained immediately before the pedalling rate decrease due to exhaustion. The highest oxygen consumption attained, in the 30 seconds exercise schedule, was taken as maximal oxygen consumption ( $\mathrm{VO}_{2} \max$ ).

We also determined the $\mathrm{VO}_{2}$ and workload (W) attained at the first and second ventilatory thresholds $\left(\mathrm{VO}_{2} \mathrm{VT}_{1}\right.$, $\left.\mathrm{WVT}_{1}, \mathrm{O}_{2} \mathrm{VT}_{2}, \mathrm{WVT}_{2}\right)$. The first ventilatoary threshold $\left(\mathrm{VT}_{1}\right)$ was localized using the criteria described by Wasserman (35) for the identification of the ventilatory threshold i.e., $\mathrm{W}$ or $\dot{\mathrm{VO}}_{2}$ at which (1) $\dot{\mathrm{V}}_{\mathrm{E}}$ began to increase nonlinearly compared to $\dot{\mathrm{VO}}_{2}$, (2) carbon dioxide output $\left(\mathrm{VCO}_{2}\right)$ began to increase nonlinearly compared to $\mathrm{VO}_{2}$, (3) $\mathrm{V}_{\mathrm{E}} / \mathrm{VO}_{2}$ exhibited a systematic increase without a concomitant increase in $\mathrm{V}_{\mathrm{E}} / \dot{\mathrm{VCO}}_{2}$, (4) expiratory oxygen fraction $\left(\mathrm{F}_{\mathrm{c}} \mathrm{O}_{2}\right)$ exhibited a systematic increase without a concomitant increase in $\mathrm{FeCO}_{2}$. The second ventilatory threshold $\left(\mathrm{VT}_{2}\right)$ was defined as the $\mathrm{W}$ or the $\dot{\mathrm{VO}}_{2}$ at which (1) $\dot{\mathrm{V}}_{\mathrm{E}}$ showed a second loss of its linear relationship with $\dot{\mathrm{VO}}_{2},(2)$ $\dot{\mathrm{V}}_{\mathrm{E}} / \dot{\mathrm{VCO}}_{2}$ began systematically to increase, (3) $\mathrm{F}_{\mathrm{e}} \mathrm{CO}_{2}$ began to decrease.

Secondly, we assessed the anaerobic capacity (AnC) expressed as the maximal accumulated $\mathrm{O}_{2}$ deficit (MAOD). Two days later, the subjects came back to the laboratory and underwent five submaximal exercises at an intensity of $200,220,240,260$ and $280 \mathrm{~W}$. All the tests were carried out at a fixed pedal rate of $90 \mathrm{rpm}$. The duration of each bout was set at 6 minutes and we took the mean of the last three minutes as $\mathrm{VO}_{2}$ for each load. In all cases, our subjects reached steady state conditions after the third minute of exercise. We estimated individually the $\mathrm{O}_{2}$ demand by extrapolating the linear relationship between the power and the $\mathrm{O}_{2}$ demand previously established. One hour after ending the last submaximal load the subjects performed a supramaximal bout at an intensity producing exhaustion between 2 and 4 minutes. The accumulated $\mathrm{O}_{2}$ demand was calculated by multiplying the $\mathrm{O}_{2}$ demand by the supramaximal test duration. The MAOD was computed as the difference between the accumulated $\mathrm{O}_{2}$ demand and the $\mathrm{O}_{2}$ consumed during the supramaximal rides.

Between 7 and 10 days after the exercise tests, the subjects came back to our laboratory, under fasting condi- 
tions, for collection of saliva. After 30 minutes of rest, each subject was provided with a plastic tube and rinsed their oral cavity with water. Afterwards, at 9 a.m., they began to deposit saliva into the tubes until a volume of $3 \mathrm{ml}$ was reached. The time spent in the collection procedure ranged between 5 and 10 minutes. The saliva samples were centrifuged and preserved at $-70^{\circ} \mathrm{C}$ until analyzed. Salivary testosterone concentrations were assessed by a radioimmunoassay method based on a Farmos Diagnostica kit (90460 Oulunsalo, Finland). The intra and interassay imprecision coefficients were $8.9 \%$ and $12 \%$ respectively at physiological concentrations. The reference values obtained in 25 males, aged between 20 and 40 years, were $0.37 \pm$ $0.13 \mathrm{nmol} / 1$. Increment of testosterone ( $\# \Delta \mathrm{T}$ ) was defined as the individual difference between the second determination and the first one. Salivary cortisol concentration were analyzed by a radioimmunoassay method using a Clinical Assays kit (Stillwater MN 55082-0285). The intra and interassay imprecision coefficients were $6.5 \%$ and $9.4 \%$ respectively at physiological concentrations. Increment of cortisol $(\Delta \mathrm{C})$ was also defined as the individual difference between the second determination and the first one.

The reference values for salivary cortisol, obtained in 20 males aged between 18 and 50 years, were $18.9 \pm$ $7.8 \mathrm{nmol} / 1$.

\section{Statisticala analysis}

The results are given as mean \pm one standard deviation. The changes in physical fitness parameters and hormone levels were verified by means of the Wilcoxon signedranks test. The steady state relationship between $\mathrm{VO}_{2}$ and workload was obtained by linear regression. The longitudinal differences in cycling economy $\left(\mathrm{VO}_{2}\right.$ at $200,220,240,260$ and 280 W) were determined by analysis of variance for repeated measures. When these $\mathrm{F}$ test were significant, individual comparisons were made by the Wilcoxon signed-ranks test. The relationship between lean body mass and delta-testosterone was assessed by using the Pearson correlation test. The statistical level of significance was set at 0.05 .

\section{Results}

The physical characteristics and training changes of the subjects are described in Table 1 . We found a significant increase in their aerobic physical fitness as assessed by the augment in their $\mathrm{Wmax}, \mathrm{WVT}_{1}$ and $\mathrm{WVT}_{2}$. However, the variables $\mathrm{VO}_{2} \mathrm{VT}_{1}, \mathrm{VO}_{2} \mathrm{VT}_{2}$ and $\mathrm{VO}_{2}$ max showed a non-significant increasing pattern. After training, the $\mathrm{VO}_{2}$-workload relationship was shifted to the right, nevertheless this shift was only significant when the $\mathrm{VO}_{2}$ was expressed as absolute value, i.e. $\mathrm{mI} \cdot \mathrm{min}^{-1}$, but not when it was adjusted for body weight (see Fig. 1).

On the other hand, the anaerobic capacity, as reflected by the MAOD, decreased from $75.8 \pm 13.9$ to $53.3 \pm$ $16.6 \mathrm{ml} \cdot \mathrm{kg}^{-1}(\mathrm{p}<0.05)$.

The subjects also underwent a significant decrease in weight (from $64.8 \pm 3.7$ to $62.5 \pm 2.8 \mathrm{~kg}, \mathrm{p}<0.05$ ) and in lean body mass (from $60.6 \pm 3.5$ to $58.5 \pm 3.0 \mathrm{~kg}, \mathrm{p}<$ $0.05)$
Table 1 Characteristics of the 7 cyclists near the onset of the season and 6 months later at the height of the competitive period.

\begin{tabular}{|c|c|c|c|}
\hline \multirow{2}{*}{$\frac{\text { Variable }}{\text { Age }}$} & \multirow{2}{*}{$\begin{array}{c}\text { First assessment } \\
21.0 \pm 3.2\end{array}$} & \multicolumn{2}{|c|}{ Second assessment } \\
\hline & & & \\
\hline Height $(\mathrm{cm})$ & $171.4 \pm 2.6$ & & \\
\hline Weight $(\mathrm{kg})$ & $64.7 \pm 3.7$ & $62.5 \pm$ & 2.8 \\
\hline$\%$ Body fat & $6.5 \pm 0.8$ & $6.3 \pm$ & 0.8 \\
\hline LBM (kg) & $60.6 \pm 3.5$ & $58.5 \pm$ & $2.9^{*}$ \\
\hline $\mathrm{VO}_{2} \max \left(\mathrm{ml} \cdot \mathrm{kg}^{-1} \cdot \mathrm{min}^{-1}\right)$ & $75.7 \pm 4.8$ & $75.3 \pm$ & 3.5 \\
\hline$W \max (W)$ & $371.4 \pm 46.0$ & $380.0 \pm$ & 28.3 \\
\hline$W \max \left(W \cdot \mathrm{kg}^{-1}\right)$ & $5.7 \pm 0.5$ & $6.1 \pm$ & $0.3^{*}$ \\
\hline $\mathrm{VO}_{2} \mathrm{VT}_{1}\left(\mathrm{ml} \cdot \mathrm{kg}^{-1} \cdot \mathrm{min}^{-1}\right)$ & $51.7 \pm 6.2$ & $54.1 \pm$ & 5.3 \\
\hline$W V T_{1}\left(W \cdot \mathrm{kg}^{-1}\right)$ & $3.6 \pm 0.5$ & $4.0 \pm$ & $0.5^{\star}$ \\
\hline $\mathrm{VO}_{2} \mathrm{VT}_{2}\left(\mathrm{ml} \cdot \mathrm{kg}^{-1} \cdot \mathrm{min}^{-1}\right)$ & $62.5 \pm 7.2$ & $65.1 \pm$ & 3.4 \\
\hline$W T_{2}\left(W \cdot \mathrm{kg}^{-1}\right)$ & $4.4 \pm 0.6$ & $4.9 \pm$ & $0.4^{\star}$ \\
\hline $\mathrm{VO}_{2} 240 \mathrm{~W}\left(\mathrm{ml} \cdot \mathrm{kg}^{-1}\right)$ & $55.5 \pm 4.3$ & $53.5 \pm$ & 3.2 \\
\hline $\operatorname{MAOD}(\mathrm{ml} \cdot \mathrm{kg}-1)$ & $75.8 \pm 4.3$ & $53.3 \pm$ & $16.6^{\star}$ \\
\hline Overall volume $(\mathrm{km})$ & & $12414.0 \pm$ & 204.0 \\
\hline Races volume $(\mathrm{km})$ & & $4528.0 \pm$ & 803.0 \\
\hline
\end{tabular}

LBM is the lean body mass; VO2max is the maximal oxygen consumption; $W$ max is the maximal workload; $V_{2} V_{1}, W V T_{1}, V_{2} V_{2}$ and $W T_{2}$ are the oxygen consumption and the workload attained at the first and second ventilatory thresholds, respectively; $\mathrm{VO}_{2} 240 \mathrm{~W}$ is the steady state oxygen consumption corresponding to an intensity of $240 \mathrm{~W} ; \mathrm{MAOD}$ is the maximal accumulation oxygen deficit expressed as $\mathrm{ml} \cdot \mathrm{kg}^{-1}$. The overall volume parameter includes training and races. Values are expressed as the mean $\pm \mathrm{SD}$. ${ }^{*} p<0.05$.

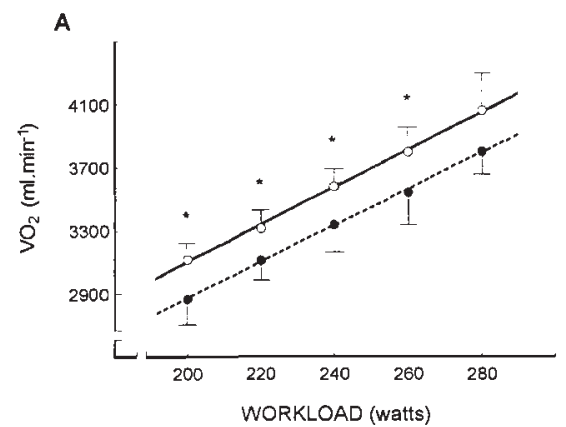

Fig. $1 \mathrm{VO}_{2}$-workload relationship (cycling economy) at the onset of the study (solid line and open circles) and at the height of the competitive period (broken line and filled circles). The $\mathrm{VO}_{2}$ values are expressed in $\mathrm{ml}$. $\min ^{-1}$ (top) and in $\mathrm{ml} \cdot \mathrm{kg}^{-1} \cdot \mathrm{min}^{-1}$ (bottom). The circles represent the mean of the 7 cyclists, while the standard deviation is depicted by vertical bars. ${ }^{*} \mathrm{p}<0.05$, when comparing the results obtained at the study onset with those corresponding to the height of the competitive period

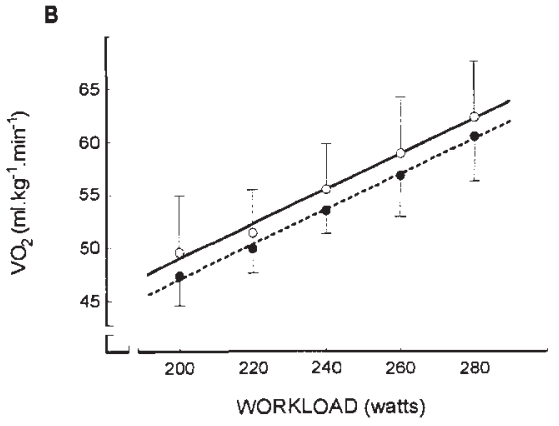

The individual relationships between the exercise done during the season and both the concomitant changes in the hormonal values and in the most relevant physical fitness parameters assessed are shown in Table 2. Salivary testosterone showed a non-significant decreasing pattern (from $0.45 \pm 0.17$ to $0.39 \pm 0.18 \mathrm{nmol} / \mathrm{l}, \mathrm{p}=0.15$ ). The individual values remained within the normal range, but decreased in 5 of the 7 subjects studied. Salivary cortisol showed a non-significant tendency to 
Table 2 Individual changes in salivary steroids and physical fitness when comparing the values at the end of the study with those found at first evaluation.

\begin{tabular}{|c|c|c|c|c|c|c|c|c|c|c|}
\hline Subjects & $\begin{array}{l}\text { Overall V. } \\
(\mathrm{km})\end{array}$ & $\begin{array}{l}\text { Races V. } \\
(\mathrm{km})\end{array}$ & $\begin{array}{c}\Delta \text { Weight } \\
(\mathrm{kg})\end{array}$ & $\begin{array}{c}\Delta \mathrm{LBN} \\
(\mathrm{kg})\end{array}$ & $\begin{array}{l}\Delta \text { Cortisol } \\
\left(\left.\mathrm{nmol} \cdot\right|^{-1}\right)\end{array}$ & $\begin{array}{c}\Delta \text { Testosterone } \\
\left(\mathrm{nmol} \cdot \mathrm{I}^{-1}\right)\end{array}$ & $\Delta T / C$ & $\begin{array}{c}\Delta W \max \\
(W)\end{array}$ & $\begin{array}{l}\triangle M A O D \\
\left(\mathrm{ml} \cdot \mathrm{kg}^{-1}\right)\end{array}$ & $\begin{array}{c}\Delta \mathrm{VO}_{2} 240 \mathrm{~W} \\
\left(\mathrm{ml} \cdot \mathrm{kg}^{-1} \cdot \mathrm{min}^{-1}\right)\end{array}$ \\
\hline 1 & 9000 & 3000 & -6.3 & -5.8 & 4.6 & -0.18 & -0.016 & 0.25 & -9.7 & 2.7 \\
\hline 2 & 7000 & 2200 & -1.8 & -1.7 & -8.8 & -0.03 & 0.008 & 0.84 & -39.9 & -8.9 \\
\hline 3 & 9000 & 2000 & 0.0 & 0.0 & 11.9 & 0.06 & -0.009 & 0.34 & 15.2 & -2.0 \\
\hline 4 & 13100 & 4100 & -2.8 & -2.6 & -24.2 & -0.14 & 0.002 & 0.25 & -34.6 & 1.0 \\
\hline 5 & 16800 & 8500 & -1.8 & -1.7 & 4.7 & 0.01 & -0.003 & -0.14 & -25.8 & 1.3 \\
\hline 6 & 18000 & 8500 & -2.7 & -2.5 & 6.4 & -0.13 & -0.016 & 0.88 & -31.5 & -4.5 \\
\hline 7 & 14000 & 3400 & -0.3 & -0.3 & 33.7 & -0.01 & -0.009 & 0.03 & -31.4 & -3.3 \\
\hline
\end{tabular}

Overall $\mathrm{V}$. is the amount of kilometers covered, considering training seasons and competitions altogether; Races $\mathrm{V}$. is the amount of kilometers covered in competitions; $\Delta$ Weight, $\Delta \mathrm{LBN}, \Delta$ Cortisol, $\Delta$ Testosterone, $\Delta \mathrm{T} / \mathrm{C}, \Delta \mathrm{VO}_{2} 240 \mathrm{~W}$ are the differences, between the first and the second assessment, in weight, lean body mass, salivary cortisol, salivary testosterone, salivary testosterone to cortisol ratio, maximal accumulated $\mathrm{O}_{2}$ deficit and the steady state $\mathrm{VO} 2$ at $240 \mathrm{~W}$, respectively.
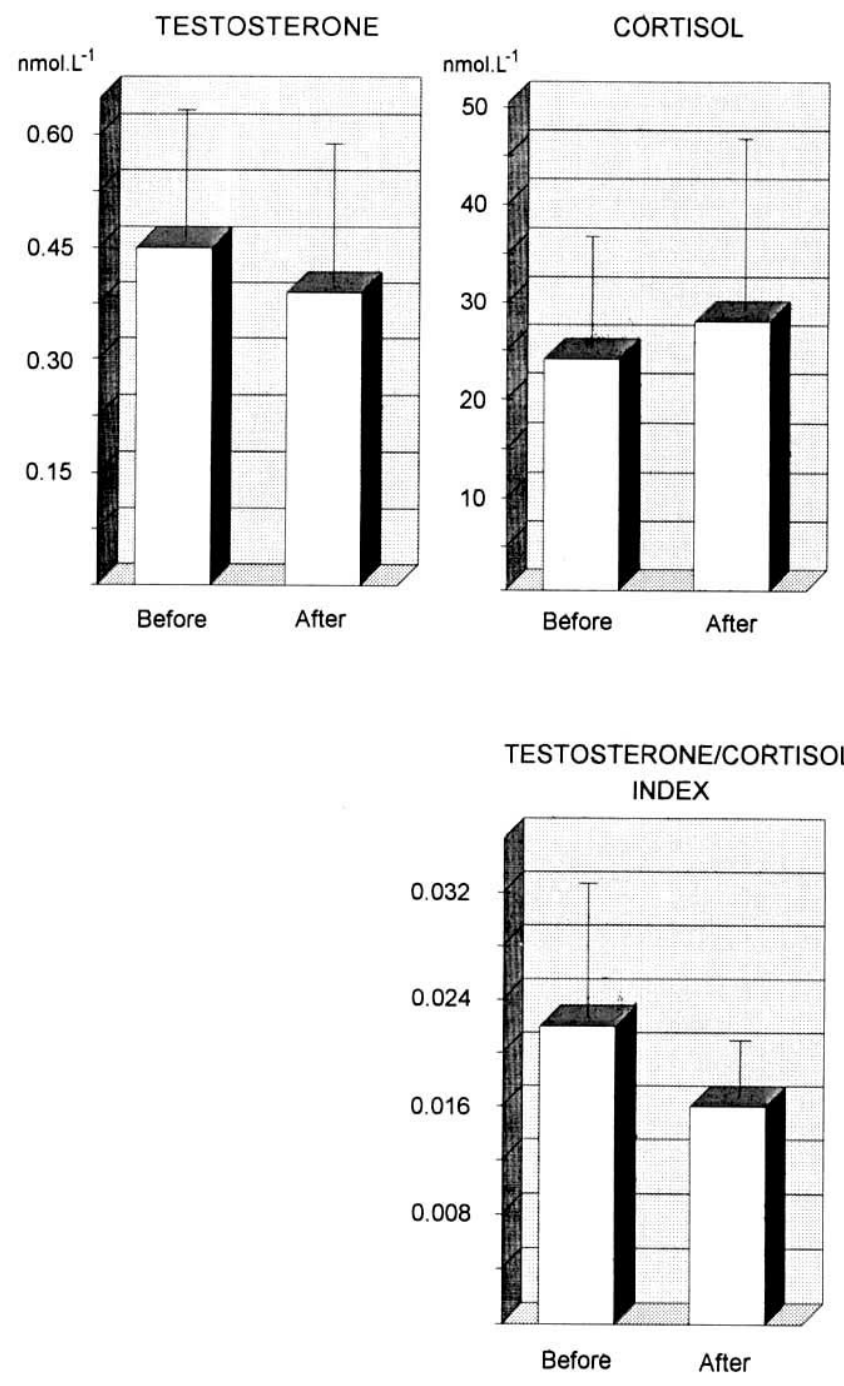

Fig. 2 Mean ( $\pm S D$ ) salivary, cortisol and testosterone/cortisol ratio at the onset of the study (before) and at the height of the competitive period (after). The changes were not significant.

increase (from $23.6 \pm 12.0 \mathrm{nmol} / 1$ to $27.5 \pm 18.9 \mathrm{nmol} / 1$ ). The individual values increased in 5 out of them and generally remained within the normal range. But in one subject, at the end

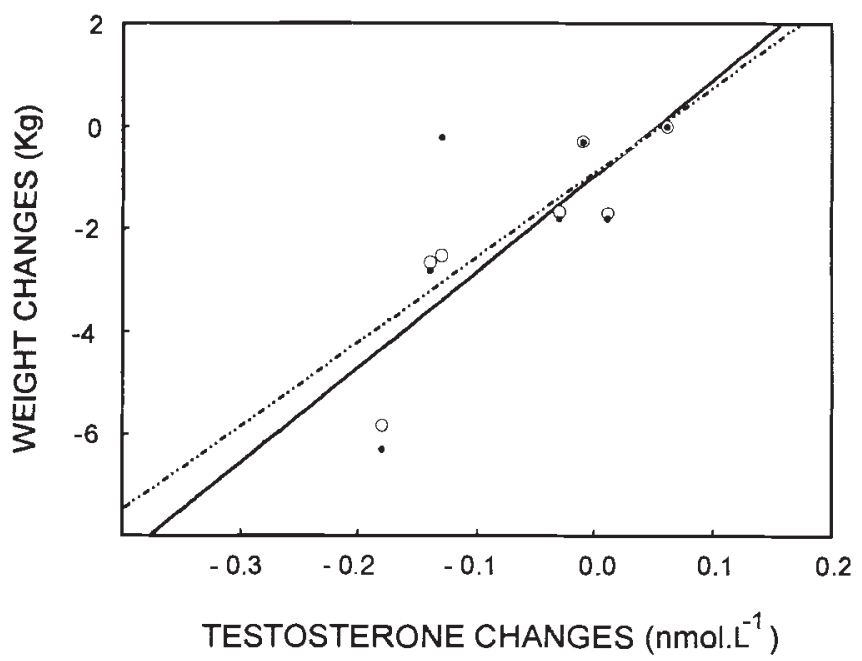

Fig. 3 Relationship between changes of testosterone with both the changes of body weight and the changes of lean body mass. Pearson correlation coefficient $r=0.87$ in both cases $(p<0.05)$.

of the study, we found a salivary cortisol value of $68.7 \mathrm{nmol} / 1$, practically doubling the concentration found at the onset of the season.

The testosterone/cortisol ratio decreased by 29 $\%$ (from $0.022 \pm 0.010$ to $0.016 \pm 0.005, p=0.10$ ), but this change did not reach significance (Fig. 2). As can be seen in Table 2, the subjects 1, 6 and 7 showed the greatest decreases in the salivary $\mathrm{T} / \mathrm{C}$ index. All these cyclists experienced salivary testosterone decrease and salivary cortisol increase. In addition, subject 6 , the one who covered most kilometers in training as well in competition, showed an accentuated decrease in both salivary testosterone and salivary $\mathrm{T} / \mathrm{C}$ index.

The individual changes of testosterone concentration have correlated with increment of weight and increment of lean body mass (Pearson $r=0.87, p<0.05$, in both cases) (Fig. 3). Nevertheless, no other correlations were found among the changes in aerobic or anaerobic physical fitness parameters and hormonal changes. Neither did we find significant correlations between testosterone and cortisol changes. 


\section{Discussion}

Recently some authors have reported the development of a certain degree of hypoandrogenism in endurance trained males $(13,30,33,34)$, including cyclists (I1). All the subjects participating in the aforementioned investigations were experienced sportsmen, who submitted themselves to very hard training programs. Other authors have carried out prospective studies on previously sedentary subjects. In contrast, they reported non-significant changes $(10,27)$ or even an increase $(22,23)$ of the basal plasma testosterone at the end of the training. It seems that the possibility of developing hypoandrogenism depends mainly on the intensity, volume and duration of the exercise program as well as the physical fitness of the individuals assessed.

The test subjects participating in our study were highly trained cyclists, as evidenced by the elevated $\mathrm{VO}_{2} \mathrm{max}$ attained in the first ergometric test $(75.7 \pm 4.8 \mathrm{ml} / \mathrm{kg} /$ $\mathrm{min}$ ), which is similar to that reported for top level athletes (6) and cyclists (29).

Although we did not observe any seasonal increase in $\mathrm{VO}_{2} \max$, we must take into account that only two determinations were made. This $\mathrm{VO}_{2} \max$ behaviour has been confirmed in professional cyclists (29) and in other sport disciplines when examining previously trained athletes repeatedly during the season (34). Nevertheless, the amount of $\mathrm{km}$ covered by our cyclists and the numerous competitions in which they participated guarantee a great degree of stress on their oxygen transport system and, probably, on their endocrine system. Although $\mathrm{VO}_{2} \max$ remained at the same level, all the subjects reported an amelioration in their field performances. In addition, the results obtained in the laboratory demonstrate an increase in their aerobic performance since the workload attained at first and second ventilatory thresholds increased as well as Wmax. An increase in Wmax, without a concomitant augment of $\mathrm{VO}_{2} \mathrm{max}$, could be justified by a greater degree of motivation when performing the second incremental exercise test, also by a more economical cycling and by an increase in anaerobic capacity. Anyway, for two reasons we think the cyclists were similarly motivated when they were tested. Firstly they were habituated to exercise testing procedures. Secondly, if they had manifested an increased level of motivation when performing the second test the anaerobic contribution to energy expenditure would have had to increase in the final step of the incremental exercise test and a $\dot{\mathrm{VO}} \mathrm{O}_{2}$-plateauing effect would have been seen. Indeed, none of the already mentioned phenomena were apparent. Since anaerobic capacity decreased, we consider that the increase in $\mathrm{WVT}_{1}, \mathrm{WVT}_{2}$ and $\mathrm{Wmax}_{\operatorname{mas}}$ mainly related to more economical cycling during the second control. Nevertheless, we must remember that the economy changes were only significant when assessed as absolute values, but not when adjusted for body weight.

To our knowledge, this is the first time that the MAOD has been assessed prospectively in high level cyclists. Our MAOD results are similar to those reported in crosssectional designed studies by others, both in active subjects (ççmedbo y tabata) and in cyclists (38).

On the other hand, cycling economy has usually been reported unchanged as a result of training $(26,31)$.
It has been suggested that the sustained increase in the plasma concentration of testosterone that accompanies prolonged exercise may disturb the normal hypothalamic GnRH releasing pattern (17). This, in turn, could lead to a pituitary malfunction causing inappropriate pulsatile release of LH and, consequently, a decrease in the basal plasma testosterone concentration (19). In contrast to MacConnie and colleagues (17), Hackney et al. (13) did not observe any effect of endurance training on the pulsatile release of LH in long-distance runners. Furthermore, in a recent prospective work, Wheeler et al. (36) have reported, in spite of a substantial decrease of the plasma testosterone and prolactin concentrations, a lack of alteration in the LH pulsatile release after 6 months of intense training in previously sedentary males. Obviously, the training intensity and volumes achieved by top athletes are so stressful that they could not be attained by sedentary people beginning a training program. That may be the reason why an impairment of the $\mathrm{LH}$ pulsatile release may contribute, at least in ultraendurance runners and elite athletes, to a diminution of plasma testosterone concentrations.

In spite of the high volume accomplished by our cyclists, we only found a non-significant tendency of both salivary testosterone and salivary $\mathrm{T} / \mathrm{C}$ index to be lower at the second control. Nevertheless, the size of the sample studied and the number of determinations done does not allow us to come to definitive conclusions. Furthermore, the cyclists showed a great individual variability in cycling volume and races. Like the majority of competitive cyclists in our country, their training program was poorly controlled, and sometimes self-planned. In addition, we decided not to modify their habits and modes of training. Considering these limitations, we will emphasize two important issues. First, our subjects who were not professionals were submitted to a high load of exercise during the season. Perhaps the volume and the intensity of exercise were not enough to provoke hypoandrogenism. However, as can be seen in Table 2, generally the subjects who showed the higher decreases in salivary testosterone and in salivary $\mathrm{T} / \mathrm{C}$ index were those who covered the most kilometers (for example, subject number 6). Also we did not find any effect of salivary testosterone and salivary $\mathrm{T} / \mathrm{C}$ index decreases on the changes in aerobic or anaerobic performance.

The plasma concentration of hormones should be regarded as a function of a dynamic equilibrium between production and clearance. It is known that plasma testosterone increases during prolonged exercise of moderate to high intensity. As testosterone is mainly removed by the liver, it has been suggested that the mechanism responsible for the plasma testosterone increase is the reduction in splanchnic blood flow during exercise (3). After exercise, splanchnic flow is reestablished enabling further uptake of steroids by the liver and, as consequence, plasma testosterone decreases. In addition, plasma testosterone may also decrease due to an impairment of Leydig cell function following exercise (7). Cortisol has been shown to influence testosterone production at the Leydig cell site. It has been reported that there is a correlation between the serum testosterone decrease and cortisol increase following stressful conditions (7).

The present data showed non-significant correlation between salivary testosterone and salivary cortisol changes. However, we must remember that the changes ob- 
served in salivary steroids were not significant, and that we only had a single value of cortisol by determination.

Wheeler et al. (36) have speculated that the chronic exposure to high levels of testosterone during exercise could prompt tissular uptake by an unknown mechanism. If this hypothetical effect remains after exercise, it will be necessary to increase testosterone production to avoid hypoandrogenism. One of the most interesting findings of Wheeler et al.'s study (36) is that sedentary subjects, engaged in an exercise program, may develop a slight hypoandrogenism.

Salivary cortisol and testosterone are a good index for evaluating the values of free serum testosterone nad cortisol, and also allow sampling at frequent intervals, avoiding the interference produced by the stress of venipunctures $(21,24$, 32 ). Since the determinations of salivary steroids are a good estimate of the bioavailability of both steroids, we can address the influence of salivary steroids changes upon androgen dependent tissues, like skeletal muscles. It is noteworthy to point out that we have observed a correlation between the basal salivary testosterone changes and lean body mass changes. Therefore, the cyclists showing the most accentuated descent in salivary testosterone presented the greatest decrease in lean body mass. Muscles can be regarded as a pool of amino acids that is mobilized in response to the systemic metabolic needs. Cortisol and testosterone play a crucial role in the regulation of protein metabolism and muscle mass. Cortisol promotes proteolysis, Type II fíbers being affected most (2). Testosterone, in contrast, increases the muscular uptake of amino acids and the rate of protein synthesis. Thus, the balance between the cortisol proteolytic action and the anticatabolic activity of testosterone seems to determine the increase or diminution of the muscle mass. Although we did not find any relationship between the changes in physical fitness and the hormonal variations, it is recognized that a diminution of the muscie cross-sectional area may lead to decreased maximal force production $(18,25)$. Moreover, a decrease of the free androgen index may further reduce the maximal force reached per unit of muscle crosssectional area $(14,15)$. Unfortunately, we did not measure force production in our cyclists, but we found a decrease in anaerobic capacity. Costill (5) reported that leg power (as expressed by vertical jumping height) was lower in trained long-distance runners than in matched sedentary control subjects. Strikingly, these runners increased their leg power after detraining. The performance in both qualities, vertical jumping and anaerobic capacity, is mainly related to Type II muscle fibers.

As far as salivary testosterone/cortisol ratio is concerned, it was lower than that reported for total plasma values $(27,34)$. This parameter showed a tendency $(p=0.10)$ to be lower at the second measurement. A reduced anabolic/catabolic ratio would perhaps permit an increased proteolysis affecting primarily type II fibers, and by this mechanism lessen maximal force production and anaerobic capacity. We think that metabolic and hormonal adaptations to high level endurance training could promote metabolic and neuromuscular changes that might be beneficial for endurance performance, but that are detrimental for anaerobic energy yield. Obviously, further studies are necessary to verify this hypothesis.

In summary, this study reveals that high level non-professional cyclists increase their aerobic physical fitness, but their anaerobic capacity deteriorates as a result of six months of combined training and competition. A decrease in their body weight as the consequence of lean body mass loss was evident, though its effect on cycling performance remains unknown. We also have detected a non-significant decrease of both salivary testosterone levels and salivary testosterone/cortisol ratio. The salivary testosterone decrease correlates with a loss of lean body mass.

\section{References}

1 Adlercreutz H., Härkonen M., Kuoppasalmi K., Näveri H., Huhtaniemi I., Tikkanen H., Remes K., Dessypris A., Karvonen J.: Effect of training on plasma anabolic and catabolic steroid hormones and their response during physical exercise. Int $J$ Sports Med 7 (Suppl): 27-28, 1986.

2 Almon R. R., Dubois D. C.: Fiber type discrimination in disuse and glucocorticoid-induced atrophy. Med Sci Sports Exerc 22: 304-311, 1990.

3 Cadoux-Hudson T. A., Few J. D., Imms F. J.: The effect of exercise on the production and clearance of testosterone in well trained young men. Eur J Appl Physiol 54: 321-325, 1985.

4 Carter J. E. L.: Body composition of Montreal Olympic Athletes. In Carter J. E. L. (ed): Physical Structure of the Olympic Athletes. Part I: The Montreal Olympic Games Anthropological Project. Medicine Sport. 16. Basel: Karger, 1982, pp 107-116.

5 Costill D. L.: The relationship between selected physiological variables and distance running performance. $J$ Sports Med Phys Fitness 7: $61-67,1967$.

${ }^{6}$ Crielaard J. M., Pirnay F.: Anaerobic and aerobic power of top athletes. Eur J Appl Physiol 47: 295-300, 1981.

7 Cumming D. C., Quigley M. E., Yen S. S. C.: Acute suppression of circulating testosterone levels by cortisol in men. J Clin Endocrinol Metab 57: 671-673, 1983.

8 Cumming D. C.: Physical activity and control of the hypothalamicpituitary-gonadal axis. Semin Reprod Endocrinol 8: 15-24, 1990.

9 Drinkwater B. L., Bruemner B., Chesnut C. H.: III. Menstrual history as determinant of current bone density in young athletes. JAMA 263: $545-548,1990$.

10 Fellmann N., Coudert J., Jarrige I. F., Bedu M., Denis C., Boucher D., Lacour J. R.: Effects of endurance training on the androgenic response to exercise in man. Int J Sports Med 6: 215-219, 1985.

11 Griffith R. D., Dressendorfer R. H., Fullbright C. D., Wade C. E. Testicular functions during exhaustive endurance training. Physician Sports Med 18: 54--64, 1990.

12 Griggs R. C., Kingston W., Jozefowiczrf, Herr B. E., Forbes G., Halliday D.: Effect of testosterone on muscle mass and muscle protein synthesis. J Appl Physiol 66: 498-503, 1989

13 Hackney A. C., Sinning W. E., Bruot B. C.: Hypothalamic-pituitarytesticular axis function in endurance-trained males. Int J Sports Med 11: $298-303,1990$

14 Häkkinen K., Pakarinen A., Alén M., Kauhanen H., Komi P. V.: Relationships between training volume, physical performance capacity, and serum hormone concentrations during prolonged training in elite weight lifters. Int J Sports Med (Suppl) 8: 61-65, 1987.

15 Häkkinen K., Keskinen K. L.: muscle cross-sectional area and voluntary force production characteristics in elite strength- and endurance-trained athletes and sprinters. Eur J Appl Physiol 59: 215220,1989

16 Highet R.: Athletic amenorrhoea. An update on aetiology, complications and management. Sports Med 7: 82-108, 1989.

17 MacConnie S. E., Barkan D. A., Lampman R. M., Schork M. A., Beitins I. Z.: Decreased hypothalamic gonadotropin-releasing hormone secretion in male marathon runners. $N$ Engl J Med 315: 411 $417,1986$.

18 Maughan R. J., Watson J. S., Weir J.: Relationship between muscle strength and muscle cross-sectional area in male sprinters and endurance runners. Eur J Appl Physiol 309-318, 1983.

19 McColl E. M., Wheeler G. D., Gomes P., Bhambhani Y., Cumming D. C.: The effects of acute exercise on LH pulsatile release in high mileage male runners. Clin Endocrinol 31: 617-629, 1989. 
20 Medbø J. I., Tabata I.: Relative importance of aerobic and anaerobic energy release during short-lasting exhausting bicycle exercise. $J$ Appl Physiol 67: 1881-1886, 1989.

21 Navarro M. A., Gómez J. M., Villabona C., Bonnin M. R.: Salivary testosterone: a good measure to reflect free testosterone. Arch Intern Med 147: 1189, 1987.

22 Peltonen P., Marniemi J., Hietanen E., Vuori I., Enholm C.: Changes in serum lipids, lipoprotein and heparin releasable enzymes during moderate physical training in man: a longitudinal study. Metabolism 30: $518-526,1981$.

23 Remes K., Kuoppasalmi K., Adlercreutz H.: Effect of long-term physical training on plasma testosterone, androstenedione, luteinizing hormone and sex-hormone-binding globulin capacity. Scand $J$ Clin Lab Invest 39: 743-749, 1979.

24 Riad-Fahmy D., Read G. F., Walker R. F., Griffiths K.: Steroids in saliva for assessing endocrine function. Endocr Rev 3: 367-395, 1982.

25 Ryushi T., Häkkinen K., Kauhanen H., Komi P. V.: Muscle fiber characteristics, muscle cross-sectional area and force production in strength athietes, physically active males and females. Scand $J$ Sports Sci 17-15, 1988.

26 Sanderson D. J.: The influence of cadence and power output on the biomechanics of force application during the steady-rate cycling in competitive and recreational cyclists. J Sports Sci 9: 191-203, 1991.

27 Seidman D. S., Lolev E., Deuster P. A., Burstein R., Arnon R., Epstein Y.: Androgenic response to long-term physical training in male subjects. Int J Sports Med 11: 421-424, 1990.

28 Siri W. E.: Body composition from fluid spaces and density: Analysis of methods. In: Techniques for Measuring Body Composition National Acad. Sci.-National Res. Council, Washington 1961, pp 223-244.

29 Sjøgaard G.: Muscle morphology and metabolic potential in elite road cyclists during a season. Int J Sports Med 5: 250-254, 1984.

30 Strauss R. H., Lanese R. R., Malarkey W. B.: Weight loss in amateur wrestlers and its effect on serum testosterone levels. JAMA 254: $3337-3338,1985$.

31 Stuart M. K., Howley E. T., Gladden L. B., Cox R. H.: Efficiency of trained subjects differing in maximal oxygen uptake and type of training. J Appl Physiol 50: 444-449, 1981.

32 Umeda T., Hiramatsu R., lwaoka T., Shimada T., Miura F., Sato T.: Use of saliva for monitoring unbound free cortisol levels in serum. Clin Chim Acta 1 10: 245-253, 1981.

33 Urhausen A., Kullmer T., Kinderman W.: A 7-week follow-up study of the behaviour of testosterone and cortisol during the competition period in rowers. Eur J Appl Physiol 56: 528-533, 1987.

34 Vervoorn C., Quist A. M., Vermulst L. J. M., Erich W. B. M., de Vries W. R., Thijssen J. H. H.: The behaviour of the plasma free testosterone/cortisol ratio during a season of elite rowing training. Int $J$ Sports Med 12: 257-263, 1991.

35 Wasserman K.: Determinants and detection of anaerobic threshold and consequences of exercise above it. Circulation 76: VI29-VI39, 1987.

36 Wheeler G. D., Singh M., Pierce W. D., Epling W. F., Cumming D. C.: Endurance training decreases serum testosterone levels in men without change in luteinizing hormone pulsatile release. J Clin Endocrinol Metab 72: 422-425, 1991.

37 Wilmore J. H., Behnke A. R.: An anthropometric estimation of body density and lean body weight in young men. $J$ Appl Physiol 27: 25 $31,1969$.

38 Withers R. T., Sherman W. M., Clark D. G., Esselbach P. C., Nolan S. R., Mackay M. H., Brinkman M.: Muscle metabolism during 30 , 60 and $90 \mathrm{~s}$ of maximal cycling on air-braked ergometer. Eur J Appl Physiol 63: 354-362, 1991.

\section{Dr. J. A. López Calbet}

Departamento de Educación Física

Universidad de Las Palmas de Gran Canaria

Perez Del Toro 1

35004, Las Palmas de Gran Canaria

Spain 